\title{
BMJ Open Pathways linking socioeconomic status to small-for-gestational-age (SGA) infants among primiparae: a birth cohort study in China
}

Xiu Luo, ${ }^{1}$ Lingfei Liu, ${ }^{1}$ Huaiting Gu, ${ }^{1}$ Fang Hou, ${ }^{1}$ Xinyan Xie, ${ }^{1}$ Xin Li, ${ }^{1}$ Heng Meng, ${ }^{1}$ Jiajia Zhang, ${ }^{2}$ Shunqing $\mathrm{Xu},{ }^{3}$ Ranran Song ${ }^{1}$

To cite: Luo X, Liu L, Gu H, et al. Pathways linking socioeconomic status to small-for-gestationalage (SGA) infants among primiparae: a birth cohort study in China. BMJ Open 2018;8:e020694. doi:10.1136/ bmjopen-2017-020694

- Prepublication history and additional material for this paper are available online. To view these files, please visit the journal online (http://dx.doi. org/10.1136/bmjopen-2017020694).

Received 17 November 2017 Revised 12 March 2018 Accepted 9 May 2018

\section{Check for updates}

${ }^{1}$ Department of Maternal and Child Health and MOE (Ministry of Education) Key Laboratory of Environment and Health, School of Public Health, Tongji Medical College, Huazhong University of Science and Technology, Wuhan, China

${ }^{2}$ Department of Epidemiology and Biostatistics, Arnold School of Public Health, University of South Carolina, Columbia, South Carolina, USA

${ }^{3}$ Key Laboratory of Environment and Health, Ministry of

Education \& Ministry of

Environmental Protection, and State Key Laboratory of Environmental Health, School of Public Health, Tongji Medical College, Huazhong University of Science and Technology, Wuhan, China

Correspondence to Dr Ranran Song; songranran@hust.edu.cn

\section{ABSTRACT}

Objectives Evidence about the relationship between socioeconomic status (SES) and small-for-gestational-age (SGA) infants was insufficient among Chinese primiparae. In addition, factors that may mediate this relationship are poorly understood. The purpose of this study was to investigate the risk of and mediators between SES and SGA.

Design Retrospective cohort study.

Setting Wuhan, Hubei, China.

Method Participants were recruited from patients who gave birth in the maternity care hospital of Wuhan between September 2012 and October 2014. Logistic regression models were used to estimate the association between SES and SGA. Pathway analysis was performed to examine the contribution of maternal lifestyles and pregnancyinduced hypertension syndrome (PIH) to the relationship between SES and SGA. Total effect, direct effect and indirect effect of SES on SGA were measured. Effect sizes were evaluated by unstandardised estimates $(B)$ and standardised estimates (B).

Results Among 8737 primiparae, 927 (10.61\%) pregnant women had babies with SGA. High SES was inversely associated with risk of SGA (OR 0.856; $95 \% \mathrm{Cl} 0.737$ to 0.995$)$ after adjustment for potential confounders. Maternal obstetric characteristics, lifestyles and PIH completely mediated SES and SGA (indirect effect: $\mathrm{B}=-0.067,95 \% \mathrm{Cl}-0.108$ to -0.026$)$. The indirect effect of SES was strengthened by PIH $(B=-0.029)$, a multivitamin supplement $(B=-0.021)$, prepregnancy body mass index $(\mathrm{BMI}) \geq 18.50(\mathrm{~B}=-0.009)$ and prepregnancy $\mathrm{BMI} \geq 18.50$ to gestational weight gain (GWG) not below the Institute of Medicine (IOM) recommendations $(B=-0.003)$.

Conclusions Women from high SES predicted lower risk of PIH, more chances to take a multivitamin supplement during early pregnancy, keeping prepregnancy BMI $\geq 18.50 \mathrm{~kg} / \mathrm{cm}^{2}$ and gaining adequate gestational weight which was not below IOM recommendations. Furthermore, lower risk of $\mathrm{PIH}$, more chances to take a multivitamin supplement, prepregnancy BMI $\geq 18.50 \mathrm{~kg} / \mathrm{cm}^{2}$ and GWG not below IOM recommendations were associated with a lower risk of SGA infants.
Strengths and limitations of this study

- It was a large population-based cohort study of pregnant women in Wuhan, China.

- Face-to-face interviews, medical records and medical measurements provided rich covariate data, which allowed us to adjust for potential confounders for small-for-gestational-age (SGA).

- Socioeconomic status (SES) index was combined with parental education and occupation. This index was more representative and reasonable to represent SES compared with using only education or occupation in China.

- This is the first study evaluating maternal lifestyles and pregnancy-induced hypertension syndrome, which mediate SES and SGA among primiparae in China.

- Some of our variables, such as a micronutrient supplement, physical activity and sleep quality during pregnancy, relied on self-report, which are subjective.

\section{INTRODUCTION}

Small-for-gestational-age (SGA) infants is defined as birth weight below the 10th percentile of a standard optimal reference population for a given gestational age and sex. ${ }^{1}$ SGA infants are at increased risk of perinatal morbidity and mortality ${ }^{2}$ as well as long-term adverse health ${ }^{3}$ and developmental outcomes. ${ }^{4}$ In 2010 , the overall prevalence of SGA infants was $27 \%$ of live births in $138 \mathrm{low} / \mathrm{middle}$-income countries, using the Alexander reference population (US National Center for Health Statistics, 1991; n=3 134879 live births). ${ }^{5}$ Another pooled country analysis research identified that the relative risks for babies who were SGA were 1.83 for neonatal mortality and 1.90 for postneonatal mortality among 20 cohorts (providing data for 2015019 live births) from Asia, Africa and Latin America. ${ }^{6}$ Therefore, it is important to recognise the 
potential risk factors for SGA infants during pregnancy so that preventive measures can be targeted at risk subgroups of pregnant women. A review from France found major risk factors identified were previous SGA birth, disease during pregnancy, maternal underweight and socioeconomic disadvantage. ${ }^{7}$ Socioeconomic disparities in SGA infants have been relatively intractable over the past decades. However, the mechanisms by which socioeconomic disadvantage leads to higher risk of SGA remain unclear.

Socioeconomic status (SES) is a complex phenomenon predicted by a broad spectrum of variables. It is often conceptualised as a combination of financial, occupational and educational influences. ${ }^{8}$ The level of SES can partly explain the risk at birth outcome,${ }^{9}$ children's anthropometric status ${ }^{10}$ and neurodevelopment. ${ }^{11}$ The risk of SGA was higher in the lower SES groups compared with the highest SES group in Finland, ${ }^{12}$ Australia, ${ }^{13}$ $\operatorname{Japan}^{9}$ and others. These estimates were based mainly on findings from developed countries, with little reliable evidence from China. Moreover, in the Hong Kong population, researchers demonstrated parental education, housing, income and occupation were not clearly linearly associated with SGA. ${ }^{14}$ As the economy of Hong Kong is more developed than that of China mainland, it makes great sense to explore the association between SES and SGA infants in mainland China.

Wang found that among 10372 people from 28 provinces of China, those from high SES promoted their health via health-related lifestyles. ${ }^{15}$ Another study reviewed the evidence focusing on aetiological factors that could mediate the socioeconomic disparities in intrauterine growth restriction. Factors included maternal anthropometry, micronutrients, physical activity, cigarette smoking and psychosocial factors. ${ }^{16}$ However, this review used a bibliographic method to find these evidence and it was hard to reveal mediators without the pathway analysis. Furthermore, the gap between the most and least deprived groups did not narrow for birthweight outcomes over the four decades. ${ }^{17}$ In the current study, we examined the association between SES and SGA infants and aimed to uncover one of the potential mechanisms that could show how SES affects SGA infants among Chinese primiparae in the Health Baby Cohort (HBC).

\section{METHODS}

\section{Study population}

All participants were selected from the prospective HBC study in China, which has been described elsewhere. ${ }^{18}$ It is an ongoing prospective cohort study, which aims to explore how environmental and genetic factors affect child health and development. Participants who had had a stillborn infant were excluded. Briefly, the cohort enrolled 11311 pregnant women who gave birth to a live singleton infant in the Women and Children Medical and Health-care Centre of Wuhan between
September 2012 and and October 2014. In our study, we selected 9623 primiparae, and then, we excluded another 886 participants because of missing values in at least one variable of interest, such as parental education and a multivitamin supplement. Therefore, a total of 8737 primiparae were finally included in our study. The present study was approved. All participating women provided their written informed consent at the time of recruitment.

\section{Diagnosis of SGA}

Birth weight and infant's gender were obtained from delivery records. Most of the gestational age was calculated from the date of the last menstrual period (LMP) which was recorded on their clinical cases. We estimated gestational age by B-mode ultrasound if the date of LMP could not be obtained. We did not exclude any specific gestational weeks from our studied population. Labour and delivery outcomes were extracted from birth records. Nude birth weight was measured for each infant within 1 hour after birth by trained nurses using standardised procedures. We defined SGA as a birth weight lower than the 10th percentile of our population for a given gestational age and sex. ${ }^{6}$ On the other hand, we defined appropriate-for-gestational-age (AGA) as a birth weight equal to or higher than the 10th centile for gestational age.

\section{Assessment of covariates}

The trained nurses conducted standardised face-to-face interviews with the participants after delivery. Participants were asked to complete a questionnaire that collected information on maternal age, maternal and paternal education level (years of education), occupations (eight major categories of Chinese occupation), the use of a multivitamin supplement during the first trimester of pregnancy (yes or no), physical activity during the last trimester of pregnancy (almost none, 1-2 days, 3-4 days, 5-6 days, 7 days) per week and sleep quality in the month before the birth (bad or good). Information regarding pregnancy-induced hypertension syndrome (PIH) was extracted from medical records excluding chronic hypertension. PIH was defined as 'yes' or 'no'. We calculated prepregnancy body mass index (BMI) from the self-reported prepregnancy weight in $\mathrm{kg}$ divided by height in $\mathrm{m}^{2}$. BMI was categorised into four groups based on recommendations by the Working Group on Obesity in China of the Chinese Ministry of Health: underweight $\left(<18.5 \mathrm{~kg} / \mathrm{m}^{2}\right)$; normal weight $(18.5-23.9 \mathrm{~kg} /$ $\left.\mathrm{m}^{2}\right)$; overweight $\left(24-27.9 \mathrm{~kg} / \mathrm{m}^{2}\right)$; and obese $(\geq 28 \mathrm{~kg} /$ $\left.\mathrm{m}^{2}\right) .{ }^{19}$ Gestational weight gain (GWG) was calculated by subtracting the prepregnancy weight from the weight measured within 3 days of the delivery day. GWG was also categorised as below, within or above the recommendations according to the Institute of Medicine (IOM). Specifically, GWG within the IOM recommendations was defined as $12.5-18.0 \mathrm{~kg}, 11.5-16.0 \mathrm{~kg}, 7.0-11.5 \mathrm{~kg}$ and $5.0-9.0 \mathrm{~kg}$ for underweight, normal weight, overweight and obese women, respectively. ${ }^{20}$ Finally, we changed prepregnancy BMI and GWG by IOM recommendations as dichotomous 
variable (prepregnancy BMI $<18.50$ or $\geq 18.50$; GWG below IOM recommendations or not below).

\section{Assessment of SES}

SES index was measured by a combination of the education and occupation categories. The scores of education and occupation are listed in online supplementary table 1 and online supplementary table $2 .^{21}$ SES index was measured based on the formula, $\mathrm{SES}=((0.7 *$ maternal education $)+(0.4 *$ maternal occupation $)+(0.7 *$ paternal education $)+\left(0.4^{*}\right.$ paternal occupation $) / 2 .{ }^{22}$ Finally, the SES index categorisation demonstrates that below one-third of the study population distribution had low SES and the remainder had high SES. ${ }^{23}$

\section{Statistical analysis}

First, data were described as mean \pm SD for continuous variables or as percentage for categorical variables. Differences between SGA and AGA were compared using the Student's t-test for continuous variables and $\mathrm{X}^{2}$ test for categorical variables. Pearson's correlation was carried out between studied variables. Univariate logistic regression analysis was used to assess the risk of having an SGA newborn among primiparae from low SES. Multivariate logistic regressions were used to explore the risk after adjustment for potential confounders. We selected the list of potential confounders according to two reasons as following. First, variables, such as maternal age, prepregnancy BMI, GWG and a multivitamin supplement during the first trimester of pregnancy, were significantly different between two groups according to the results of single factor analysis. Second, other confounders (sleep quality in the month before the birth, physical activity during last trimester and passive smoking during pregnancy) were all the lifestyles of pregnancy women. As these lifestyles associated with infants' birth weight were repeatedly reported by literatures, we added them in model 2 although they were not significant. Basing on model 2, we brought in PIH as another confounder in model 3. PIH was an obvious risk factor according to the literature review where women with PIH had twice the risk of having an SGA, compared with women having no $\mathrm{PIH}^{7}$

Second, we used the pathway analysis to explore the hypothesised underlying relations between variables of interest. The model was evaluated using the following goodness-of-fit: the comparative fit index $(\mathrm{CFI})>0.95$, the root mean square error of approximation (RMSEA) $<0.05$. Modification indices were used to detect misspecifications in the model. Estimation was carried out by a robust weighted least squares estimator (WLSMV). Because most of our variables were categorical variables, WLSMV was one of the best methods for analysing our data set. Effect sizes of the predictors on the outcome variables were expressed as unstandardised estimates (B) and standardised estimates (B). Indirect effect was defined as the effect of the exposure that acted through a given set of mediators of interest. Direct effect was refer to the effect of the exposure unexplained by those same mediators. ${ }^{24}$ The total effects of the predictors on the outcomes were computed by adding the indirect and direct effects together. ${ }^{25}$ Decoding of each response for further analysis was present in table 1 . All of the analyses were conducted with R 3.2.2. All $\mathrm{P}$ values reported were two-sided and 0.05 was used as significance level.

\section{Patient involvement}

No patients were involved in setting the research question or the outcome measures, nor were they involved in developing plans for recruitment, design or implementation of the study. No patients were asked to advise on interpretation or writing up of results. There are no plans to disseminate the results of the research to study participants or the relevant patient community.

\section{Table 1 Description of variables in analysis}

\begin{tabular}{|c|c|}
\hline Variables & Decoding of each response \\
\hline SES & $0=$ ='low', 1='high' \\
\hline GWG by IOM recommendations & $0=$ ='below', 1='within and above' \\
\hline Prepregnancy BMI & $0==^{\prime}<18.5^{\prime}, 1==^{`} \geq 18.5^{\prime}$ \\
\hline Physical activity during the last trimester of pregnancy & $\begin{array}{l}0=\text { 'almost none per week', } 1=' 1-2 \text { days per week', } 2=\text { ' } 3- \\
4 \text { days per week', } 4=\text { = } 5-6 \text { days per week', } 5=\text { = } 7 \text { days per } \\
\text { week' }\end{array}$ \\
\hline Sleep quality in the month before the birth & $0=$ ='bad', 1 ='good' \\
\hline A multivitamin supplement during the first trimester of pregnancy & $0=$ ='no', 1 ='yes' \\
\hline Infant's gender & $0=$ ='girl', $1=$ ='boy' \\
\hline Passive smoking during pregnancy & $0=$ =no', 1 ='yes' \\
\hline $\mathrm{PIH}$ & $0=$ 'no', 1 ='yes' \\
\hline Maternal age & Continuous variable \\
\hline SGA & $0=$ ='no', 1='yes' \\
\hline
\end{tabular}

BMI, body mass index; GWG, gestational weight gain; IOM, Institute of Medicine; PIH, pregnancy-induced hypertension syndrome; SES, socioeconomic status; SGA, small-for-gestational-age. 
Table 2 Characteristics of participants with SGA and AGA among primiparae in Wuhan, China $(n=8737)$

\begin{tabular}{|c|c|c|c|c|}
\hline \multirow[b]{2}{*}{ Variables } & \multirow[b]{2}{*}{$\mathrm{n}(\%)$ or Mean \pm SD } & \multirow{2}{*}{$\begin{array}{l}\text { SGA } \\
n(\%) \text { or Mean } \pm S D\end{array}$} & \multirow{2}{*}{$\begin{array}{l}\text { AGA } \\
n(\%) \text { or Mean } \pm S D\end{array}$} & \multirow[b]{2}{*}{$\mathbf{P}$ values } \\
\hline & & & & \\
\hline \multicolumn{5}{|c|}{ GWG by IOM recommendations } \\
\hline Below & $901(10.31)$ & $208(22.44)$ & $693(8.87)$ & $<0.001$ \\
\hline Within and above & $7836(89.69)$ & $719(77.56)$ & $7117(91.13)$ & \\
\hline \multicolumn{5}{|l|}{ Prepregnancy BMI } \\
\hline$<18.5$ & $2082(23.83)$ & $309(33.33)$ & $1773(22.70)$ & $<0.001$ \\
\hline$\geq 18.5$ & $6655(76.17)$ & $618(66.67)$ & $6037(77.30)$ & \\
\hline \multicolumn{5}{|c|}{ Physical activity during the last trimester of pregnancy } \\
\hline Almost none per week & $834(9.55)$ & $79(8.52)$ & $755(9.67)$ & 0.495 \\
\hline $1-2$ days per week & $831(9.51)$ & $86(9.28)$ & $745(9.54)$ & \\
\hline 3-4 days per week & $663(7.59)$ & $61(6.58)$ & $602(7.71)$ & \\
\hline $5-6$ days per week & $146(1.67)$ & $17(1.83)$ & $129(1.65)$ & \\
\hline Every day per week & $6263(71.68)$ & $684(73.79)$ & $5579(71.43)$ & \\
\hline \multicolumn{5}{|c|}{ Sleep quality in the month before the birth } \\
\hline Bad & $3063(35.06)$ & $310(33.44)$ & $2753(35.25)$ & 0.275 \\
\hline Good & $5674(64.94)$ & $617(66.56)$ & $5057(64.75)$ & \\
\hline \multicolumn{5}{|c|}{ A multivitamin supplement during the first trimester of pregnancy } \\
\hline No & $3640(41.66)$ & $434(46.82)$ & $3206(41.05)$ & 0.001 \\
\hline Yes & $5097(58.34)$ & $493(53.18)$ & $4604(58.95)$ & \\
\hline \multicolumn{5}{|l|}{ Infant's gender } \\
\hline Boy & $4499(51.49)$ & $467(50.38)$ & $4032(51.63)$ & 0.517 \\
\hline Girl & $4238(48.51)$ & $460(49.62)$ & $3778(48.37)$ & \\
\hline \multicolumn{5}{|c|}{ Passive smoking during pregnancy } \\
\hline No & $7717(88.33)$ & $813(87.7)$ & $6904(88.40)$ & 0.532 \\
\hline Yes & $1020(11.67)$ & $114(12.3)$ & $906(11.60)$ & \\
\hline Maternal age & $27.70 \pm 3.24$ & $27.32 \pm 3.50$ & $27.75 \pm 3.21$ & $<0.001$ \\
\hline \multicolumn{5}{|l|}{$\mathrm{PIH}$} \\
\hline No & 8468 (96.92) & $882(95.15)$ & $7586(97.13)$ & 0.001 \\
\hline Yes & $269(3.08)$ & $45(4.85)$ & $224(2.87)$ & \\
\hline \multicolumn{5}{|l|}{ SES } \\
\hline Low & 2933 (33.60) & $361(38.94)$ & $2572(32.93)$ & $<0.001$ \\
\hline High & $5804(66.40)$ & $566(61.06)$ & $5238(67.07)$ & \\
\hline
\end{tabular}

AGA, appropriate-for-gestational-age; BMI, body mass index; GWG, gestational weight gain; IOM, Institute of Medicine; PIH, pregnancyinduced hypertension syndrome; SES, socioeconomic status; SGA, small-for-gestational-age.

\section{RESULTS}

\section{Study population}

A total of 8737 primiparae met our criterion and they were finally included in our study. The mean maternal age was $27.70 \pm 3.24$ years. The range of gestational age was $28-42$ weeks. In total, $927(10.61 \%)$ infants were diagnosed with SGA. There were 4499 boys and 4238 girls with a boy to girl ratio of 1.06 .

\section{Characteristics of the sample}

The basic demographic characteristics among SGA are presented in table 2. Mean maternal age was younger, mean prepregnancy BMI was lower and GWG below IOM recommendations was more likely with women who had SGA infants. Compared with women with AGA infants, women with SGA infants were more likely to have PIH and came from low SES. Women with AGA infants tended to be more positive regarding taking a multivitamin supplement during the first trimester of pregnancy. Correlations of the variables are presented in online supplementary table 3 .

\section{Associations between SES and SGA}

To examine the association between SES and the risk of SGA, univariate and multivariate logistic regression models were used in table 3. Compared with women 
Table 3 Associations of SES with SGA among 8737 primiparae in Wuhan, China

\begin{tabular}{lllll}
\hline SGA & SES & OR & 95\% Cl & P values \\
\hline Model 1 & Low & Ref & & \\
& High & 0.770 & 0.669 to 0.886 & $<0.001$ \\
Model 2 & Low & Ref & & \\
& High & 0.846 & 0.728 to 0.983 & 0.029 \\
Model 3 & Low & Ref & & \\
& High & 0.856 & 0.737 to 0.995 & 0.043 \\
\hline
\end{tabular}

Model 1, unadjusted model; model 2, adjusted for maternal age, prepregnancy body mass index, gestational weight gain, a multivitamin supplement during the first trimester of pregnancy, sleep quality in the month before the birth, physical activity during last trimester and passive smoking during pregnancy; model 3 adjusted as model 2 plus pregnancy-induced hypertension syndrome.

SES, socioeconomic status; SGA, small-for-gestational-age.

with low SES, the OR of SGA was 0.770 (95\% CI 0.669 to 0.886) for those with high SES, in the unadjusted model. After adjustment for potential confounders, the ORs of SGA were 0.846 (95\% CI 0.728 to 0.983 ) and $0.856(95 \%$ CI 0.737 to 0.995 ) in model 2 and model 3, respectively.

\section{Mediation model for SGA}

We proposed a hypothetical model for SGA in figure 1, including the mediators PIH, a multivitamin supplement during first trimester, prepregnancy BMI, GWG by IOM recommendations, physical activity during the last trimester of pregnancy and sleep quality in the month before the birth. Covariates (maternal age and passive smoking during pregnancy) were added in pathway analysis to control potential relations. Table 4 listed SGA with the best CFI and RMSEA, which were 0.012 and 0.967 . This model revealed that maternal obstetric characteristics, lifestyles and PIH completely mediated SES and SGA. The indirect effect of SES was strengthened in SGA $(\mathrm{B}=-0.067,95 \% \mathrm{CI}-0.108$ to -0.026$)$ via PIH $(\mathrm{B}=-0.029$, $\mathrm{P}=0.021)$, a multivitamin supplement $(\mathrm{B}=-0.021, \mathrm{P}$ $=0.010)$, prepregnancy $\mathrm{BMI} \geq 18.5(\mathrm{~B}=-0.009, \mathrm{P}=0.010)$ and prepregnancy $\mathrm{BMI} \geq 18.5$ to GWG not below IOM recommendations $(\mathrm{B}=-0.003, \mathrm{P}=0.007)$.

In our model, the indirect effect came from the coefficient 'a' multiplied by coefficient 'b'. For example, woman with high SES had more chances of taking a multivitamin supplement $(\mathrm{B}=0.317, \quad \mathrm{P}<0.001)$. Then, multivitamin supplement taking decreased the SGA $(\mathrm{B}=-0.066, \mathrm{P}<0.05)$. Thus, the indirect effect of SES to SGA was $0.317^{*}-0.066=-0.021$ through taking a multivitamin supplement.

\section{DISCUSSION}

The findings of our study indicated that high SES was related to a reduced risk of SGA after adjustment for

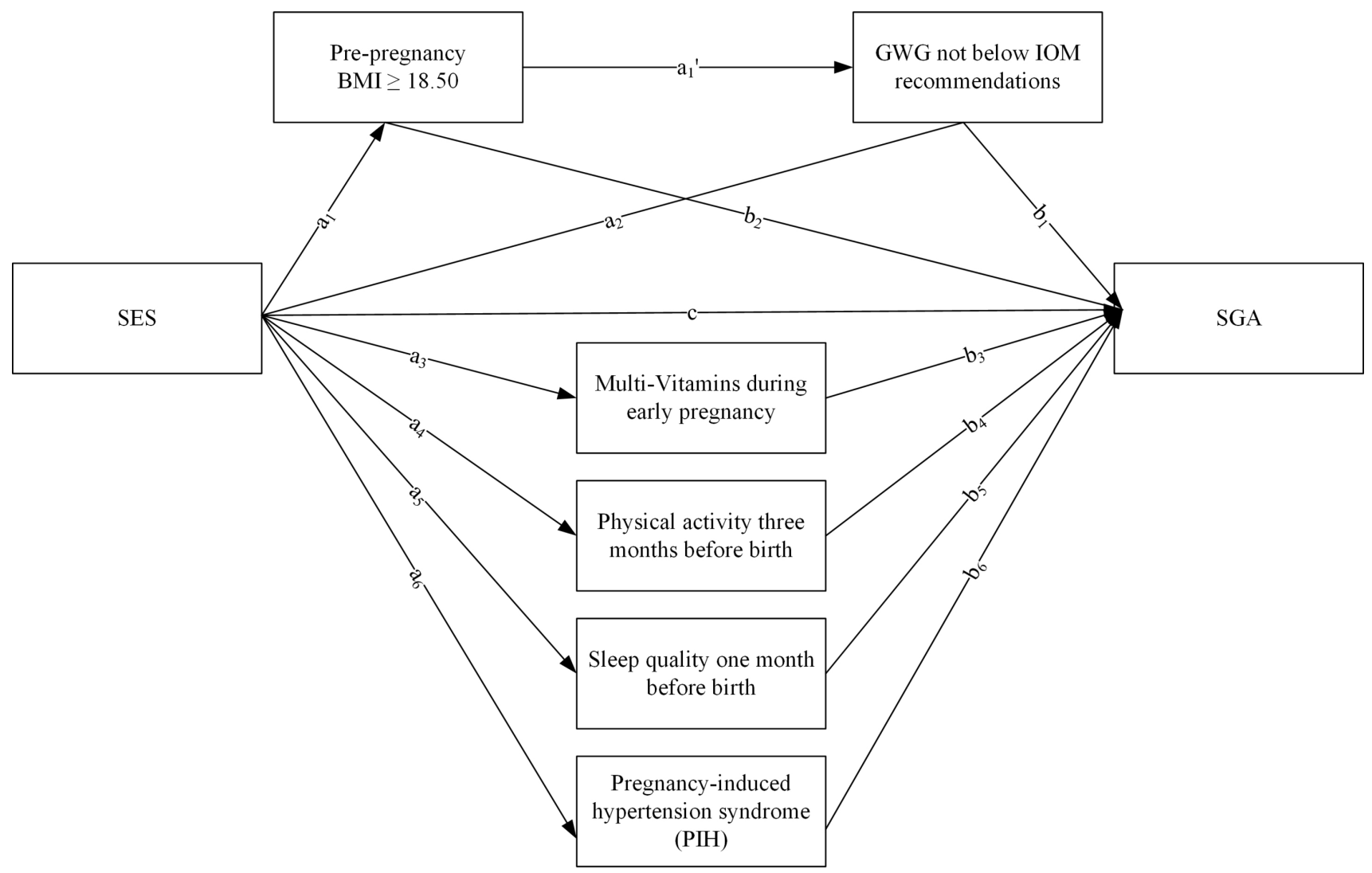

Figure 1 Serial mediation models of the indirect associations of socioeconomic status (SES) and small-for-gestational-age (SGA). Unstandardised regression coefficients are a1, a1', a2, a3, a4, a5, a6, b1, b2, b3, b4, b5, b6, c. Adjusted for maternal age and passive smoking during pregnancy. BMI, body mass index; GWG, gestational weight gain; IOM, Institute of Medicine. 
Table 4 Indirect and total effects of socioeconomic status and maternal characteristics and lifestyles during pregnancy on SGA

\begin{tabular}{|c|c|c|c|c|c|c|c|}
\hline & SES $\rightarrow$ mediators & $\begin{array}{l}\text { Mediators } \rightarrow \text { birth } \\
\text { outcomes }\end{array}$ & B & & & & \\
\hline Pathway & a & b & $\mathbf{a}^{*} \mathbf{b}$ & SE & $95 \% \mathrm{Cl}$ & values & B \\
\hline \multicolumn{8}{|c|}{ Small-for-gestational-age (SGA) } \\
\hline Total effect & & & -0.067 & & & & -0.030 \\
\hline Direct effect (c) & & & -0.046 & 0.044 & $(-0.132$ to 0.040$)$ & 0.299 & -0.034 \\
\hline Indirect effect & & & -0.067 & 0.021 & $(-0.108$ to -0.026$)$ & 0.001 & -0.030 \\
\hline $\begin{array}{l}\text { SES } \rightarrow \text { Prepregnancy } \\
\mathrm{BMI} \geq 18.50 \rightarrow \text { GWG } \\
\text { not below IOM } \\
\text { recommendations }\end{array}$ & $0.033^{\star},-0.253^{\star *}$ & $0.321^{* *}$ & -0.003 & 0.001 & $(-0.005$ to -0.001$)$ & 0.007 & -0.001 \\
\hline $\begin{array}{l}\text { SES } \rightarrow \text { GWG not below IOM } \\
\text { recommendations }\end{array}$ & -0.045 & $0.321^{* *}$ & -0.014 & 0.013 & $(-0.039$ to 0.011$)$ & 0.273 & -0.006 \\
\hline $\begin{array}{l}\text { SES } \rightarrow \text { Prepregnancy } \\
\mathrm{BMI} \geq 18.50\end{array}$ & $0.033^{*}$ & $-0.274^{\star \star}$ & -0.009 & 0.003 & $(-0.015$ to -0.003$)$ & 0.010 & -0.004 \\
\hline $\begin{array}{l}\text { SES } \rightarrow \text { a multivitamin } \\
\text { supplement during the first } \\
\text { trimester of pregnancy }\end{array}$ & $0.317^{\star \star}$ & $-0.066^{*}$ & -0.021 & 0.008 & $(-0.037$ to -0.005$)$ & 0.010 & -0.009 \\
\hline $\begin{array}{l}\text { SES } \rightarrow \text { Physical activity } \\
\text { during the last trimester of } \\
\text { pregnancy }\end{array}$ & $0.284^{\star \star}$ & 0.017 & 0.005 & 0.003 & $(-0.001$ to 0.011$)$ & 0.063 & 0.002 \\
\hline $\begin{array}{l}S E S \rightarrow \text { Sleep quality in the } \\
\text { month before the birth }\end{array}$ & $0.150^{\star \star}$ & 0.027 & 0.004 & 0.004 & $(-0.004$ to 0.012$)$ & 0.297 & 0.002 \\
\hline $\mathrm{SES} \rightarrow \mathrm{PIH}$ & $-0.176^{*}$ & $0.166^{\star *}$ & -0.029 & 0.013 & $(-0.054$ to -0.004$)$ & 0.021 & -0.013 \\
\hline
\end{tabular}

Covariates of maternal age, passive smoking during pregnancy were adjusted for SGA.

${ }^{*} \mathrm{P}<0.05 ;{ }^{* \star} \mathrm{P}<0.001$.

$\mathrm{BMI}$, body mass index; CFI, comparative fit index; GWG, gestational weight gain; IOM, Institute of Medicine; PIH, pregnancy-induced hypertension syndrome; RMSEA, the root mean square error of approximation; SES, socioeconomic status.

potential confounders. In the pathway analysis, PIH, taking a multivitamin supplement during early pregnancy, keeping normal prepregnancy BMI and gaining reasonable gestational weight were all the significant mediators which completely mediated the relationship between SES and SGA. There were four pathways between SES and SGA as following. (1) High SES of pregnancy women predicted lower risk of PIH. The risk of SGA was reduced by no PIH. (2) Women from high SES had more chances to take a multivitamin supplement during early pregnancy. A multivitamin supplement could lead to a lower risk of SGA infants. (3) Women from high SES were more likely to have a prepregnancy BMI $\geq 18.50 \mathrm{~kg} / \mathrm{cm}^{2}$. Furthermore, prepregnancy BMI $\geq 18.50 \mathrm{~kg} / \mathrm{cm}^{2}$ decreased the risk of SGA infants afterwards. (4) Women from high SES predicted prepregnancy BMI $\geq 18.50 \mathrm{~kg} / \mathrm{cm}^{2}$. Pregnancy women with prepregnancy BMI $\geq 18.50 \mathrm{~kg} / \mathrm{cm}^{2}$ could gain adequate gestational weight which was not below IOM recommendations. And the GWG not below IOM recommendations decreased the risk of SGA infants.

One of the strengths of our study was the large sample size. In addition, face-to-face interviews, medical records and measurements provided rich covariate data, which allowed us to adjust for potential confounders for SGA. Third, SES index was combined with parental education and occupation. This index was more representative and reasonable to represent SES compared with using only education or occupation in China. We acknowledge that there were also some limitations. First, information on education and occupation was obtained using faceto-face questionnaires, which might have bias. Occupation can fluctuate over time, and it is more likely to lead to misclassification. Second, although we carefully adjusted for several potential confounders for SGA, we were unlikely to fully rule out the possibility of residual confounding by other unmeasured factors such as parents' history of SGA and maternal stress during pregnancy. Third, some of our variables including a micronutrient supplement, physical activity and sleep quality during pregnancy relied on self-reporting, which were subjective.

Predictably, high SES was a protector of SGA in our study. A large population-based study from Finland reported that SES determined by women's occupation was inversely associated with the risk of SGA. ${ }^{12}$ 
A birth cohort study conducted in France reported that low SES determined by neighbourhood deprivation may affect fetal growth, especially in rural areas. ${ }^{26}$ These two studies were consistent with our results. However, Clayborne et al did not find a direct association between SES measured by neighbourhood deprivation and the risk of SGA in Canada. ${ }^{27}$ Because of the different measures of SES, these studies may not be easily compared. The underlying mechanisms responsible for increased risk of SGA among primiparae with low SES remain speculative. In our study, we found that some mediators could completely mediate SES and SGA.

In the pathway analysis, we observed that PIH was a mediator between SES and SGA. We demonstrated that SES was associated with PIH among primiparae. A meta-analysis including 51 studies found that low SES was associated with higher blood pressure. This association was particularly evident in the level of education. ${ }^{28}$ Adherence to knowledge of hypertension and more social resources to maintain healthy behaviours could explain why SES likely affects PIH among pregnant women. The rate of SGA infants from the PIH group was significantly higher compared with the no PIH group in our study. PIH is associated with a reduction in placental perfusion, which influences the size of the placenta. ${ }^{29}$ In SGA infants, the size of the placental disc was smaller and the birth weight was lighter. ${ }^{30}$ Placenta is an important organ for fetus and supplies all the nutrients needed for fetal development. The pathology of placenta was potentially causing or contributing to SGA and hypertension was one of the factors in aetiology. ${ }^{31}$ The growth and development of the placenta being influenced by PIH may be suggested an explanation for lower birth weight. ${ }^{30}$

Taking a multivitamin supplement during the first trimester of pregnancy was another mediator between SES and SGA. Women with low SES defined by family income had less chances to obtain optimal nutrient supplements in a meta-analysis including 12 randomised controlled trials. ${ }^{32}$ A double-blind cluster randomised controlled trial in rural China reported birth weight was $42 \mathrm{~g}$ higher in the multiple micronutrients group compared with the folic acid group. ${ }^{33}$ Another birth cohort from Denmark reported that regular periconceptional multivitamins use was associated with a reduced risk of SGA births. ${ }^{34}$ A multivitamin supplement during early pregnancy might reduce the risk of alcohol use in relation to SGA. ${ }^{35}$ This result evidenced that a multivitamin supplement during early pregnancy was a protector factor for SGA, which was similar to our study. Multivitamins are important for human physical function and they play vital roles in numerous metabolic processes and physiological functions in the human body. A multivitamin supplement during pregnancy reduced the risk of pregnancy complications, involving oxidative stress and pre-eclampsia. Pre-eclampsia could decrease blood to the placenta, which causes growth retardation. ${ }^{36}$ In China, most people believe that they should obtain vitamins from daily diet, that is, fresh vegetables and fruits, which is a natural way instead of taking multivitamin supplements every day. Pregnant women are recommended to take multivitamin supplements, since they are unable to obtain an adequate nutrient status from their diet alone. Most pregnant women take folic acid, because the government provides folic acid free of charge. For the multivitamin supplements, pregnant women decide to take them or not depending on their own opinions. The different dietary habits and customs might explain part of why taking multivitamin supplements is significant. Our results showed that high SES was significantly related to a daily supplement of multivitamin. As our large-scale studied population came from the city of Wuhan, the results of our study could extend to pregnant women in Hubei province, which included 12 cities. However, extrapolation of our findings to Chinese women should be cautious. Multicentre cohort studies from different cities of China will be needed in further studies.

Prepregnancy underweight and prepregnancy underweight to GWG below IOM recommendations were the two pathways between SES and SGA. The chances of having an SGA infant was significantly higher among underweight women compared with normal prepregnancy BMI in our study, which was consistent with a study in Lebanon. As Lebanon is a developing country in Asia, and its people are similar to Chinese people, we deemed these results could support our findings. Smoking, poor diet and medical illness like anaemia, which are risk factors for SGA among underweight women, occurred more often. Deficiency of maternal plasma volume among underweight women has been suggested as a cause of SGA. ${ }^{37}$ In our study, underweight women were more likely to have insufficient weight gain during pregnancy and below normal weight gain significantly increased the odds of SGA. As expected, GWG below IOM recommendations in women who were underweight prepregnancy was reportedly more likely to affect the birth weight of their neonates. ${ }^{38}$ Poor nutrition or unhealthy psychological state among pregnant women with GWG below IOM recommendations may explain causes of SGA.

\section{CONCLUSION}

We demonstrated that SES was inversely associated with SGA after adjustment for potential confounders among primiparae. In this population, we also found that mediators could completely mediate SES and SGA. Monitoring of blood pressure, avoiding prepregnancy underweight, keeping sufficient GWG during pregnancy and taking a multivitamin supplement during the first trimester of pregnancy are practical 
and feasible measures to reduce the risk of SGA. As we all know, SGA is a public health issue and SES disparities are difficult to change over a short time. It had great sense to maintain normal blood pressure and keep a healthy lifestyle to reduce cases of SGA infants among primiparae, especially for women of childbearing age who have a low SES. A future research direction should focus on identifying interventions to successfully reduce socioeconomic disparities in SGA.

Acknowledgements The authors would like to thank the staff at the Women and Children Medical and Healthcare Centre of Wuhan for their support. They also would like to thank all participants in this study for their voluntary participation.

Contributors XL contributed to acquisition of data, statistical analysis, interpretation of data and manuscript writing. LL, HG, FH, XX, XL, HM and SX contributed to interpretation of the data. JZ, RS supervised the project and wrote the manuscript. All authors approved the final version to be published. RS is the guarantor of this work.

Funding This work was supported by National Natural Science Foundation of China (81673194, 21437002 and 81372959). Project from Health and Family Planning Commission of Hubei Province (WJ2015MB019).

Competing interests None declared.

Patient consent Obtained.

Ethics approval Tongji Medical College, Huazhong University of Science and Technology, and the Women and Children Medical and Healthcare Centre of Wuhan.

Provenance and peer review Not commissioned; externally peer reviewed. Data sharing statement № additional data are available.

Open access This is an open access article distributed in accordance with the Creative Commons Attribution Non Commercial (CC BY-NC 4.0) license, which permits others to distribute, remix, adapt, build upon this work non-commercially, and license their derivative works on different terms, provided the original work is properly cited and the use is non-commercial. See: http://creativecommons.org/ licenses/by-nc/4.0/

( $)$ Article author(s) (or their employer(s) unless otherwise stated in the text of the article) 2018. All rights reserved. No commercial use is permitted unless otherwise expressly granted.

\section{REFERENCES}

1. Alexander GR, Himes JH, Kaufman RB, et al. A United States national reference for fetal growth. Obstet Gynecol 1996;87:163-8.

2. Qiu X, Lodha A, Shah PS, et al. Neonatal outcomes of small for gestational age preterm infants in Canada. Am J Perinatol 2012;29:87-94.

3. Risnes KR, Vatten LJ, Baker JL, et al. Birthweight and mortality in adulthood: a systematic review and meta-analysis. Int $\mathrm{J}$ Epidemiol 2011;40:647-61.

4. Mwaniki MK, Atieno M, Lawn JE, et al. Long-term neurodevelopmental outcomes after intrauterine and neonatal insults: a systematic review. Lancet 2012;379:445-52.

5. Lee AC, Katz J, Blencowe $\mathrm{H}$, et al. National and regional estimates of term and preterm babies born small for gestational age in 138 lowincome and middle-income countries in 2010. Lancet Glob Health 2013;1:e26-e36.

6. Mikolajczyk RT, Zhang J, Betran AP, Meersseman W, Verschueren P, Tousseyn T, et al. A global reference for fetal-weight and birthweight percentiles. Lancet 2011;377:1855-61.

7. Gaudineau A, Prevalence GA. [Prevalence, risk factors, maternal and fetal morbidity and mortality of intrauterine growth restriction and small-for-gestational age]. J Gynecol Obstet Biol Reprod 2013;42:895-910.

8. Huang $\mathrm{H}$, Wan Mohamed Radzi CW, Salarzadeh Jenatabadi H. Family environment and childhood obesity: a new framework with structural equation modeling. Int J Environ Res Public Health 2017; $14: 181$

9. Fujiwara T, Ito J, Kawachi I. Income inequality, parental socioeconomic status, and birth outcomes in Japan. Am J Epidemiol 2013;177:1042-52.
10. Herzog B, Lacruz ME, Haerting J, et al. Socioeconomic status and anthropometric changes-a meta-analytic approach from seven German cohorts. Obesity 2016;24:710-8.

11. Patra K, Greene MM, Patel AL, et al. Maternal education level predicts cognitive, language, and motor outcome in preterm infants in the second year of life. Am J Perinatol 2016;33:738-44.

12. Räisänen $\mathrm{S}$, Gissler M, Sankilampi U, et al. Contribution of socioeconomic status to the risk of small for gestational age infants-a population-based study of 1,390,165 singleton live births in Finland. Int J Equity Health 2013;12:28-8.

13. Ng SK, Cameron CM, Hills AP, et al. Socioeconomic disparities in prepregnancy $\mathrm{BMI}$ and impact on maternal and neonatal outcomes and postpartum weight retention: the EFHL longitudinal birth cohort study. BMC Pregnancy Childbirth 2014;14:314.

14. Leung JY, Leung GM, Schooling CM. Socioeconomic disparities in preterm birth and birth weight in a non-Western developed setting: evidence from Hong Kong's 'Children of 1997' birth cohort. $J$ Epidemiol Community Health 2016;70:1074-81.

15. Wang F, Sociology DO. Socioeconomic Status, lifestyle and health inequality. Chinese Journal of Sociology 2012;32:125-43.

16. Kramer MS, Séguin L, Lydon J, et al. Socio-economic disparities in pregnancy outcome: why do the poor fare so poorly? Paediatr Perinat Epidemiol 2000;14:194-210.

17. Glinianaia SV, Ghosh R, Rankin J, et al. No improvement in socioeconomic inequalities in birthweight and preterm birth over four decades: a population-based cohort study. BMC Public Health 2013;13:345.

18. Song L, Shen L, Li H, et al. Socio-economic status and risk of gestational diabetes mellitus among Chinese women. Diabet Med 2017;34:1421-7.

19. Zhou BF. Predictive values of body mass index and waist circumference for risk factors of certain related diseases in Chinese adults-study on optimal cut-off points of body mass index and waist circumference in Chinese adults. Biomed Environ Sci 2002;15:83-96.

20. Zhou A, Xiong C, Hu R, et al. Pre-pregnancy BMl, gestational weight gain, and the risk of hypertensive disorders of pregnancy: a cohort study in Wuhan, China. PLoS One 2015;10:e0136291.

21. Zhao SC, Xia M, Tang JC, et al. Associations between metabolic syndrome and clinical benign prostatic hyperplasia in a northern urban Han Chinese population: A prospective cohort study. Sci Rep 2016;6:33933.

22. Zhai $\mathrm{Y}$, Sulayiman $\mathrm{X}$, Li WR, Wr L, et al. [The relationship between socioeconomic status and overweight and obesity among elementary school children in China]. Zhonghua Yu Fang Yi Xue Za Zhi 2013;47:945-8

23. Gavin AR, Morris J. The association between maternal early life forced sexual intercourse and offspring birth weight: the role of socioeconomic status. J Womens Health 2017;26:442-9.

24. Richiardi L, Bellocco R, Zugna D. Mediation analysis in epidemiology: methods, interpretation and bias. Int J Epidemiol 2013;42:1511-9.

25. Kantomaa MT, Stamatakis E, Kankaanpää A, et al. Physical activity and obesity mediate the association between childhood motor function and adolescents' academic achievement. Proc Natl Acad Sci U S A 2013;110:1917-22.

26. Bertin M, Viel JF, Monfort C, et al. Socioeconomic disparities in adverse birth outcomes in Urban and rural contexts: a french motherchild cohort. Paediatr Perinat Epidemiol 2015;29:426-35.

27. Clayborne ZM, Giesbrecht GF, Bell RC, et al. Relations between neighbourhood socioeconomic status and birth outcomes are mediated by maternal weight. Soc Sci Med 2017;175:143-51.

28. Leng B, Jin Y, Li G, et al. Socioeconomic status and hypertension: a meta-analysis. J Hypertens 2015;33:221-9.

29. Chisholm KM, Folkins AK. Placental and clinical characteristics of term small-for-gestational-age neonates: a case-control study. Pediatr Dev Pathol 2016;19:37-46.

30. Phad N, Dahlstrom JE, Ellwood D, et al. The effect of pregnancyinduced hypertensive disorders on placental growth along short and long axes and neonatal outcomes. Aust N Z J Obstet Gynaecol 2015;55:239-44.

31. Thorne J, Downey P, Mooney EE. Placental pathology associated with small for gestational age infants. Ir Med J 2014;107:249-50.

32. Ronsmans C, Fisher DJ, Osmond C, et al. Maternal Micronutrient Supplementation Study Group. Multiple micronutrient supplementation during pregnancy in low-income countries: a meta-analysis of effects on stillbirths and on early and late neonatal mortality. Food Nutr Bull 2009;30:S547-S555.

33. Zeng L, Dibley MJ, Cheng Y, et al. Impact of micronutrient supplementation during pregnancy on birth weight, duration of gestation, and perinatal mortality in rural western China: double blind cluster randomised controlled trial. BMJ 2008;337:a2001. 
34. Catov JM, Bodnar LM, Olsen J, et al. Periconceptional multivitamin use and risk of preterm or small-for-gestational-age births in the Danish National Birth Cohort. Am J Clin Nutr 2011;94:906-12.

35. Avalos LA, Kaskutas L, Block G, et al. Does lack of multinutrient supplementation during early pregnancy increase vulnerability to alcohol-related preterm or small-for-gestational-age births? Matern Child Health J 2011;15:1324-32.
36. Roberts JM, Cooper DW. Pathogenesis and genetics of preeclampsia. Lancet 2001;357:53-6.

37. Buschur E, Kim C. Guidelines and interventions for obesity during pregnancy. Int J Gynaecol Obstet 2012;119:6-10.

38. Savitz DA, Stein CR, Siega-Riz AM, et al. Gestational weight gain and birth outcome in relation to prepregnancy body mass index and ethnicity. Ann Epidemiol 2011;21:78-85. 